\title{
Participatory decision-making for cancer care in a high-risk sample of low income Mexican-American breast cancer survivors: The role of acculturation
}

\author{
Maribel Cervantes-Ortega ${ }^{1}$, Senxi Du ${ }^{2}$, Kelly A. Biegler ${ }^{3}$, Sadeeka Al-Majid ${ }^{4}$, Katelyn C. Davis ${ }^{3}$, Yunan Chen ${ }^{5}$, Alfred \\ Kobsa ${ }^{5,6}$, Dana B. Mukamel ${ }^{3}$, Dara H. Sorkin*3 \\ ${ }^{1}$ Department of Epidemiology, University of California Irvine, Irvine, USA \\ ${ }^{2}$ Keck School of Medicine, University of Southern California, Los Angeles, USA \\ ${ }^{3}$ Department of Medicine, University of California Irvine, Irvine, USA \\ ${ }^{4}$ School of Nursing, California State University Fullerton, Fullerton, USA \\ ${ }^{5}$ Department of Informatics, University of California Irvine, Irvine, USA \\ ${ }^{6}$ Department of Computer Science, University of California Irvine, Irvine, USA
}

Received: December 17, 2019

Accepted: April 7, 2020

Online Published: May 6, 2020

DOI: $10.5430 /$ ijh.v6n2p35

URL: https://doi.org/10.5430/ijh.v6n2p35

\begin{abstract}
Background: Despite declining cancer incidence and mortality rates, Latina patients continue to have lower 5-year survival rates compared to their non-Hispanic white counterparts. Much of this difference has been attributed to lack of healthcare access and poorer quality of care. Research, however, has not considered the unique healthcare experiences of Latina patients.

Methods: Latina women with prior diagnoses of stage 0 -III breast cancer were asked to complete a cross-sectional survey assessing several socio-demographic factors along with their experiences as cancer patients. Using a series of linear regression models in a sample of 68 Mexican-American breast cancer survivors, we examined the extent to which patients' ratings of provider interpersonal quality of care were associated with patients' overall healthcare quality, and how these associations varied by acculturation status.

Results: Findings for Latina women indicated that both participatory decision-making (PDM) $(\beta=0.62, p<.0001)$ and trust ( $\beta$ $=0.53, p=.02)$ were significantly associated with patients' ratings of healthcare quality. The interaction between acculturation and PDM further suggested that participating in the decision-making process mattered more for less acculturated than for more acculturated patients $(\beta=-0.51, p \leq .01)$.

Conclusions: The variation across low and high acculturated Latinas in their decision-making process introduces a unique challenge to health care providers. Further understanding the relationship between provider-patient experiences and ratings of overall healthcare quality is critical for ultimately improving health outcomes.
\end{abstract}

Key Words: Quality of care, Interpersonal quality of care, Participatory decision-making, Trust, Latina, Breast cancer survivor

\section{INTRODUCTION}

In the United States alone, approximately 276,480 new cases of invasive breast cancer are expected to be diagnosed in
2020 along with 48,530 new cases of non-invasive (in situ) breast cancer. ${ }^{[1]}$ Furthermore, a projected total of 42,170 U.S. women are expected to die from breast cancer in the

*Correspondence: Dara H. Sorkin; Email: dsorkin@uci.edu; Address: 100 Theory, Suite 120, Irvine, CA 92617, USA. 
same year, reflecting the highest cancer death rate after lung cancer. ${ }^{[1]}$ As of January 2020, there are more than 3.5 million women with a history of breast cancer living in the United States. ${ }^{[1]}$ Although breast cancer continues to be major source of disease, early detection and advances in treatment have resulted in higher survival rates. It is, therefore, crucial to consider the experiences of breast cancer survivors during their treatment process.

Within the past few decades, patients have become increasingly active in their own medical care. Recently diagnosed cancer patients are faced with the complexities of not only coping with the emotional stress of their diagnosis but also comprehending extensive information about treatment procedures immediately after diagnosis in order to participate in the decision-making process with their providers. Although the initial diagnosis may be challenging, many patients tend to seek additional information and later return to their healthcare providers as informed patients rather than as passive recipients of advice and treatment. ${ }^{[2]}$

As the availability and complexity of treatment options has increased, studies have shown that patients who have a higher quality provider-patient relationship and are concurrently guided through the treatment process, are more satisfied with their care. ${ }^{[3,4]}$ The model in which providers actively engage patients with their own medical care has been termed "shared" or "participatory decision-making" (PDM). ${ }^{[5,6]}$ Ideally, a PDM style approach involves a provider-patient relationship in which patients are presented with the best available information. Patients' values, goals, capabilities and care preferences are also assessed, and together with their healthcare team, providers and patients arrive at mutually agreedupon treatment plans. The perception that the provider involves them in the treatment decision-making process has been associated with improved health outcomes, better selfmanagement, and higher levels of patient satisfaction. ${ }^{[7,8]}$ In turn, satisfaction with care in the area of breast cancer has been associated with better illness-management and health behaviors, including improved adherence to recommended therapy, ${ }^{[9]}$ leading to improved health outcomes and quality of life. ${ }^{[10-12]}$

Recent studies, however, have reported a disparity in PDM among Latina patient populations, as they have the lowest rates of PDM and poorest provider-patient communication compared to their non-Hispanic white counterparts. ${ }^{[13]}$ Latinas with breast cancer, and in particular low acculturated Latinas, are less likely to report high clinical communication quality for both surgeons and medical oncologists, ${ }^{[13]}$ less informed about their diagnoses and less likely to seek or receive information about their treatment options compared to other racially/ethnically diverse women. ${ }^{[14]}$ Surprisingly, a large population-based cohort study examining satisfaction with care that included low-income Latina women suggested that most women (nearly $75 \%$ ) reported being extremely satisfied with the breast cancer care they had received, and that less acculturated Latinas had nearly five times the odds of being extremely satisfied compared to non-Hispanic white women. ${ }^{[15]}$ However, these studies have been descriptive in nature and have not taken further steps toward understanding how patient-ratings of their provider experiences contribute to ratings of their healthcare quality.

The noted paradoxical finding may arise, in part, from the limited consideration of acculturation factors, which may influence expectations around not only provider-patient communication and confidence in participating throughout the treatment decision-making process, but also expectations of received care from the medical system. ${ }^{[15,16]}$ Studies examining racial/ethnic differences in patient perspectives when it comes to their cancer treatment experiences have found that lower acculturated Latinas are less likely to report high communication quality with their clinicians and that Spanishspeaking Latinas had the highest odds of low satisfaction with their surgical treatment decisions. ${ }^{[13,17,18]}$ However, there is growing evidence that first generation Hispanic immigrants have higher levels of satisfaction with care than second or later generation Hispanic patients. ${ }^{[19]}$ Given the evidence that lower health literacy and language barriers are often associated with lower ratings of participatory decision making, lower satisfaction with the treatment decision making process, ${ }^{[20,21]}$ and more treatment regret, ${ }^{[21]}$ it is difficult to disentangle the potentially opposing influence of factors related to acculturation and immigration-related barriers to care.

This raises the question as to whether the strong association between participatory decision-making and satisfaction with care generalizes to Latina women or is limited to those of a certain acculturation level, and more importantly whether there are other components of the provider-patient relationship that warrant examination. Therefore, this study was designed to examine (1) associations between patient ratings of the interpersonal qualities of the provider-patient relationship and their overall healthcare quality, and (2) the extent to which patient acculturation levels affected these associations, in a sample of Mexican-American breast cancer survivors.

\section{METHODS}

\subsection{Study design and participants}

Latina breast cancer survivors were recruited through an academic medical center and asked to complete a survey assessing several socio-demographic factors along with their 
experiences as cancer patients. Inclusion criteria comprised the following: 1) identifying as Mexican-American, 2) at least 18 years of age, 3 ) prior diagnosis of stage 0 -III breast cancer, 4) have completed active treatment 6 months prior to recruitment, 5) have a body mass index $>25 \mathrm{~kg} / \mathrm{m}^{2}$ and $<43$, and 6) English or Spanish speaking. Reasons for exclusion included the following: 1) Stage IV (e.g., metastatic disease), 2) recurrent cancer, 3 ) contraindications for moderate physical activity (i.e., walking), 4) visual or hearing impairment, or 5) any major psychiatric and/or life-threatening illness that impeded the ability to consent to or complete the study. Approximately 77 women were approached, and 70 consented to complete a survey in their preferred language (either English or Spanish) containing measures that assessed their level of acculturation and other socio-demographic characteristics, patient-perceived quality of care, and satisfaction with care. In order to accommodate language preferences within this sample, all study materials were made available in either Spanish or English to avoid any inclusion bias based on language. Study procedures were approved by the University of California, Irvine Institutional Review Board.

\subsection{Measures}

\subsubsection{Outcome measures}

Evaluation of overall quality of care was assessed using a single item that asked patients to rate the quality of care they received over the course of their cancer treatment. The item used a 5-point Likert scale, in which a higher score indicated better quality of care $(1=$ Poor, $5=$ Excellent $)$.

\subsubsection{Provider-patient relationship measures}

Level of patient involvement in decision-making related to their breast cancer treatment was assessed using a 4-item measure of participatory decision making (PDM-4). ${ }^{[22,23]}$ Participatory decision making scales have consistently been used across all racial/ethnic groups, with some studies specifically focusing on minority groups. ${ }^{[22,24,25]}$ A sample item included "How often did the doctors that took care of you during your cancer treatment offer you choices in your medical care?" Ratings were made on a 5-point Likert scale $(1=$ never/none of the time, $5=$ very often/all of the time). Items were averaged to create a composite variable (Cronbach's alpha was adequate $=0.89$ ). To assess patient perceptions of being treated as an equal partner, we used a single item question rated on a 5-point scale $(1=$ definitely yes, $5=$ definitely no). A total of five questions were used to assess patients' trust in their provider. ${ }^{[26]}$ A sample item included "How often do you feel that you trust your doctor's judgments about your medical care?" Ratings were made on a 5 -point scale ( $1=$ never, $5=$ always). Items were averaged to form a composite measure (Cronbach's alpha $=0.84$ ).

Published by Sciedu Press

\subsubsection{Acculturation status}

Acculturation status was assessed using a combination of information from three content areas: 1) whether or not the participant was born in the U.S. $(0=$ no, $1=$ yes $)$; 2$)$ length of time in the U.S. (those who had lived in the U.S. for less than 10 years, between 10 and 20 years, and 20 or more years); and 3) primary language spoken ( 1 = English-speaking only or English better than Spanish, 2 = equal proficiency in both English and Spanish, and 3 = Spanish-speaking only or Spanish better than English).

Data was combined to create a point scale from 0 to 3 (0 = born outside the U.S. and lived in the U.S. for less than 10 years, 1 = born outside the U.S. and lived in the U.S. for 10-20 years, 2 = born outside the U.S. and lived in the U.S. for 20 or more years, 3 = born in the U.S.). The categories applied to language spoken were assigned a point scale from 0 to 2 ( 0 = Spanish-speaking, 1 = both equally, 2 $=$ English-speaking).

Scores were then added together to create a composite acculturation score, which ranged from 0 (least acculturated) to 5 (most acculturated). Participants were dichotomized into a less acculturated group (scores $=0-2$ ) and a more acculturated group (scores $=3-5$ ). This scoring system was modeled after a study on Hispanic and Chinese populations, reflecting a more accurate representation of acculturation compared to separate analyses of each variable, as these variables tend to cluster within individuals. ${ }^{[27]}$

\subsubsection{Covariates}

Covariates in the analysis included standard demographic characteristics, such as age and years of education. Participants also reported their date of diagnosis, as well as the time passed since their last chemotherapy or radiation treatment. Participants were asked about the length of relationship with their doctor $(1=$ less than one month, $2=$ more than 1 month but less than a year, $3=1-2$ years, $4=$ more than two but less than five years, $5=5$ or more years). Health insurance status was reported $(0=$ no insurance, $1=$ insurance $)$, as well as insurance type ( 1 = insurance provided by job or employer, 2 = MediCal, 3 = CalOptima, 4 = MSI, 5 = Medicare, etc. .

\subsection{Statistical analysis}

All data were analyzed using SPSS release 17.0 (SPSS Inc., Chicago) and SAS/STAT software version 9.4 (SAS Institute Inc., Cary, NC, USA.). All derived multi-item measures were tested for reliability using Cronbach's alpha. We first describe the sociodemographic and health characteristics of the patient sample. A linear regression model using full information maximum likelihood (FIML) was created to examine the effect of acculturation on the association between com- 
ponents of the interpersonal quality of the provider-patient relationship and overall patient ratings of quality of care. Interactions of acculturation were made with each interpersonal component of the provider-patient relationship to test whether quality of care was moderated by acculturation. To allow for ease of interpretation and to help account for the small sample size, acculturation was dichotomized into low acculturation (score of $\leq 2$ ) and high acculturation (scores of $\geq 3$ ).

\section{Results}

\subsection{Sample description}

A total of 70 Latina breast cancer survivors responded to the survey with 68 respondents having a non-missing quality of care value. Of the 68 respondents, Table 1 describes the 63 participants that had complete data from which level of acculturation could be calculated; of these, 42 were categorized as having lower acculturation, and 21 were categorized as having higher acculturation. Overall, the sample generally consisted of women with low socioeconomic status, as the majority of the sample is on government-sponsored insurance (e.g., MediCal/CalOptima) and $64.5 \%$ of the sample had a total annual household income less than $\$ 14,999$. Few significant differences were found when assessing sociodemographic characteristics in lower versus higher acculturated respondents in this sample. Respondents of lower acculturation were older (Means $=57.1$ years old vs. 52.2 years old, $p$ $=.12$ ) and in the U.S. for less time than their higher acculturated counterparts (Means $=28.2$ years in U.S. vs. 34.3 years in US, $p=.05)$. Furthermore, respondents of lower acculturation were also less likely to have graduated from high school (Percents $=31.0 \%$ high school graduate or more vs. $57.1 \%$ high school graduate or more, $p=.05$ ) compared to higher acculturated respondents.

Table 1. Socio-demographic characteristics by acculturation $(\mathrm{N}=63)$

\begin{tabular}{|c|c|c|c|}
\hline \multirow{3}{*}{ Items } & \multicolumn{2}{|c|}{ Acculturation } & \multirow{3}{*}{$p$-value } \\
\hline & Low $(n=42)$ & High $(n=21)$ & \\
\hline & $\%$ & $\%$ & \\
\hline Preferred Language, Spanish & 100 & 0.0 & $<.0001$ \\
\hline Education, high school graduate or more & 31.0 & 57.1 & .05 \\
\hline Born outside of the U.S., Yes & 100 & 61.9 & \\
\hline Married or living with partner, Yes & 47.6 & 39.1 & .47 \\
\hline Income, $\$ 14,999$ or less & 59.5 & 57.1 & .86 \\
\hline Insurance, Government Sponsored (e.g., MediCal) & 85.7 & 76.2 & .35 \\
\hline Medical provider speaks Spanish, Yes & 9.5 & 9.5 & 1.0 \\
\hline Time since last treatment, 5 or more years & 38.1 & 28.6 & .45 \\
\hline Items & Mean (SD) & Mean (SD) & $p$-value \\
\hline Average age, years & $57.1(10.1)$ & $52.2(12.0)$ & .12 \\
\hline Time since diagnosis, years & $5.8(3.8)$ & $5.7(4.0)$ & .94 \\
\hline Time in the US, years [only born outside US] & $28.2(9.9)$ & $34.3(8.6)$ & .05 \\
\hline \multicolumn{4}{|l|}{ Components of Provider-Patient Relationship } \\
\hline Participatory Decision-Making (PDM) & $4.5(0.7)$ & $4.1(1.0)$ & .12 \\
\hline Trust & $4.8(0.4)$ & $4.7(0.5)$ & .44 \\
\hline Treated as an Equal Partner & $4.8(0.5)$ & $5.0(0.2)$ & .15 \\
\hline \multicolumn{4}{|l|}{ Dependent Variable } \\
\hline Quality of Care & $4.7(0.7)$ & $5.0(0.2)$ & .14 \\
\hline
\end{tabular}

\subsection{Patient-perceived quality of care and satisfaction} with care

Means and standard deviations for all patient-centered care variables as well as their bivariate correlation analysis are dis- played in Table 2. All three components of patient-provider interpersonal qualities (PDM style, being treated as an equal partner, and feelings of trust) were associated with patients' ratings of overall healthcare quality. 
The results of the linear regression model testing the inter- $(\beta=0.53, p=.02)$ with an alpha $<0.05$. When assessing the action of acculturation by each interpersonal component of the provider-patient relationship on patient-reported quality of care are shown in Table 3. Significant main effects were observed for $\operatorname{PDM}(\beta=0.62, p<.0001)$ and trust in provider moderating effect of acculturation, the only significant interaction observed was between PDM style and acculturation level $(\beta=-0.51, p<.01)$.

Table 2. Means and correlations for components of the patient-provider relationship and the outcome, quality of care $(\mathrm{N}=$ 68)

\begin{tabular}{llllll}
\hline & Mean (SD) & $\mathbf{1}$ & $\mathbf{2}$ & $\mathbf{3}$ & $\mathbf{4}$ \\
\hline 1. Participatory Decision-Making (PDM) & $4.3(0.9)$ & -- & & & \\
2. Trust in Provider & $4.7(0.5)$ & $0.38^{*}$ & -- & & \\
3. Treated as an Equal Partner & $4.8(0.5)$ & $0.51^{* *}$ & $0.49^{* *}$ & -- & \\
4. Quality of Care & $4.7(0.8)$ & $0.53^{* *}$ & $0.55^{* *}$ & $0.41^{*}$ & -- \\
\hline
\end{tabular}

Table 3. Association between provider-patient relationship and patient-reported quality of care for high versus low acculturated patients $(\mathrm{N}=68)$

\begin{tabular}{|c|c|c|c|}
\hline \multirow{2}{*}{ Variables } & \multicolumn{3}{|c|}{ Quality of Care } \\
\hline & $\beta$ (SE) & $t$ & $p$-value \\
\hline \multicolumn{4}{|l|}{ Main Effects } \\
\hline Acculturation & $-0.57(3.49)$ & -0.16 & .87 \\
\hline Participatory decision making (PDM) & $0.62(0.14)$ & 4.36 & $<.0001$ \\
\hline Trust in provider & $0.53(0.22)$ & 2.43 & .02 \\
\hline Treated as an equal partner & $-0.27(0.22)$ & -1.26 & .21 \\
\hline \multicolumn{4}{|l|}{ Interactions } \\
\hline PDM x Acculturation & $-0.51(0.20)$ & -2.60 & $<.01$ \\
\hline Trust in provider $\mathrm{x}$ Acculturation & $0.18(0.34)$ & 0.54 & .59 \\
\hline Treated as an equal partner $\mathrm{x}$ Acculturation & $0.42(0.63)$ & 0.67 & .50 \\
\hline
\end{tabular}

Note. Analyses also included age and level of education as covariates.

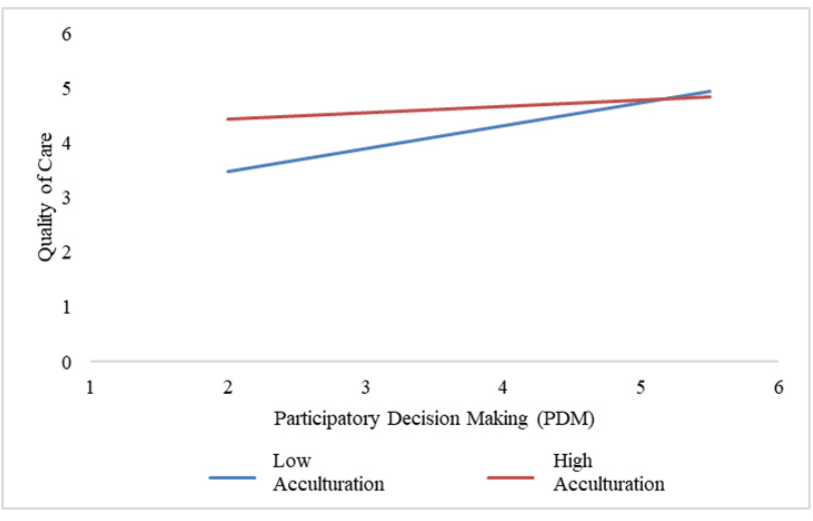

Figure 1. Crude linear association of PDM and quality of care by low and high acculturation

As shown in Figure 1, the association between PDM ratings' and ratings of overall quality of care were less strong among higher acculturated patients and more strong among lower acculturated patients.

\section{DiscUSSION}

The field of healthcare is becoming increasingly sensitive to the importance of high-quality provider-patient relationships and its role in improving patient satisfaction with care and health outcomes. The growing literature has shown that patient ratings of overall quality of care, as well as the importance of the various components of the providerpatient relationship, vary between individuals from different racial/ethnic groups. ${ }^{[13,15,28-31]}$ This study specifically set out to examine the extent to which each of three providerpatient relationship components were associated with patients' rating of their satisfaction with care. Additionally, our study investigated whether the importance of each component varied by acculturation level.

Although all components of the patient-provider relationship were correlated with one another, not all were significantly associated to ratings of quality of care in the regression analysis. Specifically, our study found that PDM was significantly associated with quality of care, such that increased levels 
of PDM were independently associated with higher patient ratings in quality of care. Similarly, a study reported that interventions designed to increase participatory/shared decision making within a group of Hispanic and other racially diverse individuals by encouraging patients to express their concerns were associated with increased perceptions in quality of care. ${ }^{[32]}$ Study results buttress these patterns suggesting that, for minority women in particular, it is uniquely important to engage patients in opportunities to voice their concerns and ask questions during their treatment process. By doing so, both patients and providers are given the opportunity to address cultural differences around expectations for participating in treatment decisions and provider-patient communication deficiencies prominent among some Latinas. In the context of receiving medical care, strong trust in health care providers has consistently been shown to guide patients' follow-up care experiences, ${ }^{[33]}$ such that increased trust has been associated with higher satisfaction with treatment and quality of care. ${ }^{[34]}$ These findings hold true in non-Hispanic ${ }^{[35-37]}$ and Hispanic ${ }^{[38]}$ populations alike. Our findings are consistent with the literature ${ }^{[36]}$ in that those who had high trust in their providers reported significantly better quality of care ratings than those who had low trust in their providers, irrespective of acculturation status. Here, patient-provider relationships high in trust may facilitate communication and decrease patient fear, resulting in higher ratings of quality of care. ${ }^{[33,37]}$ Additionally, this association may be explained, in part, by patients' needs to feel trust, that their provider is doing everything possible in order to obtain the best treatment outcome, especially after being confronted with a serious diagnosis. ${ }^{[33]}$

Furthermore, results reflected a significant interaction for participatory decision-making and acculturation level, indicating that the association between PDM ratings' and ratings of overall quality of care was weaker among higher acculturated patients and stronger among lower acculturated patients. Our findings add to the literature by showing that variations exist in the provider-patient relationship within a single ethnic group, and that a patient's acculturation level may differentially impact the association of participatory decision-making with patient ratings of satisfaction with care.

Paradoxical findings in previous studies showing that low income and low acculturated Latinas are more likely to report higher satisfaction with care ${ }^{[15]}-$ even though Latina patient populations report the lowest rates of PDM and poorest provider-patient communication compared to their nonHispanic white counterparts ${ }^{[14]}$ - highlights the importance of disentangling the role of acculturation. Growing literature continues to demonstrate that higher acculturated Latina patients are generally less satisfied with care than their lower acculturated counterparts. ${ }^{[8,15]}$ Our study similarly shows that, when it comes to the modifying effect of acculturation, associations between PDM and overall quality of care are strong among lower acculturated patients and weaker among higher acculturated patients. An explanation may be that individuals of different acculturation levels may have different perceptions of what PDM means in the context of their care. A study assessing doctor-patient relationships in the public and private health care contexts within the Mexican health care system bring attention to existing differences in expectations for these relationships. Study findings indicated that the type of medical care subsystem, public versus private, shaped different relationships between patients and doctors. ${ }^{[39]}$ Encounters between patients and physicians within public medical settings, which typically care for lowerincome patients, appear to be more doctor-centered, while these encounters become more complex in the private sector, which typically care for more affluent patients, shifting to a model where a patient-centered approach coexists with the traditional physician-centered approach. ${ }^{[39]}$ Within Mexican culture, access to public versus private health care shapes patient experiences and may play a role in expectations upon transition to the US health care system. The patients included in this study were all recruited from a medical clinic that provides care to the underserved, and thus our low-acculturated patients seen in this setting may have lower expectations for engagement with their providers in comparison to what they could expect in their country of origin. Thus, upon immigration to the US, it is likely that as women have the opportunity to become increasingly involved in the decisionmaking process, these experiences have a stronger impact on their ratings of quality of care.

On the other hand, it is also possible that Latina women who are less acculturated may be more grateful for any type of care they receive, resulting in higher ratings in quality of care as they become increasingly involved with their medical care. This conceptual framework, emphasizing deference toward providers among lower acculturated individuals, ${ }^{[38]}$ likely explains the impact of acculturation seen across our results. The idea that individuals who have not had an opportunity to extensively acculturate into the US and its health care system, especially with its emphasis on patient autonomy, are more likely to regard providers with greater respect and esteem than those who have had more opportunity to acculturate. ${ }^{[38]}$ Perhaps individuals with lower acculturation scores have not always had the same access to care and are appreciative of these providers for providing necessary care after their cancer diagnosis while higher acculturated individuals maintain high expectations for the amount of care and quality of care they receive. 
This study finds strength in its ability to add to a small but growing literature suggesting that patient preferences may be contingent on expectations driven by cultural and sociodemographic factors. ${ }^{[13]}$ Nonetheless, this study also has a few limitations. First, our sample size was relatively small and predominately comprised of low-income Mexican-American women, which may not be generalizable to other breast cancer survivor populations, Latina or otherwise. Nonetheless, this study offers a unique and interesting perspective given that recruited participants were predominantly low income, held lower education levels, and the majority were born outside the US. Second, the descriptive nature of this study prevents any assumptions of causality between the variables. Although the relationship between the provider and patient has been shown to influence patients' satisfaction with care ratings, there may be other factors, such as their impression of other health care staff and their ability to work together, receptionists, ease of navigating the healthcare system, etc., that are unaccounted for in our study and also likely influence reports of quality of care. ${ }^{[40,41]}$ It is also important to note that respondents were not asked about language or ethnic concordance with their providers, factors likely to improve communication and influence feelings of participation and trust.

Final limitations concern the measurement of quality of care and acculturation. ${ }^{[42,43]}$ Quality of care was measured using a single question and may have resulted in a crude assessment. Acculturation, on the other hand, was assessed using a combination of information from three content areas. Whereas language and nativity are commonly used as proxy measures ${ }^{[44]}$ in recent years a more comprehensive understanding of acculturation has evolved that has called for greater attention to the socio-cultural context that affect the experience of migration - including the environments from which people emigrate and to which they immigrate. ${ }^{[45]}$ For example, Allen and colleagues highlight how immigration can be accompanied by a disruption in social ties, increased stress, and experiences of discrimination. ${ }^{[46]}$ Our goal was to evaluate the extent to which acculturation influences the association between ratings of provider-patient interpersonal quality on and ratings of healthcare quality, as opposed to understanding the indirect influence of these other sociocontextual factors.

Based on the findings from our study, we demonstrated the importance of the provider-patient relationship in MexicanAmerican breast cancer survivors' satisfaction with care and aimed to bring attention to the acculturation differences in various components of these relationships. In order to improve satisfaction in health care among ethnic minority patients, there may be a need for a more tailored relationship between the provider and patient. Our findings indicate that providers should, to the best of their ability, prioritize participatory decision-making in their interactions with patients in order to improve ratings in quality of care which could have beneficial downstream and longer-term effects for patient health. Future research should continue to focus on larger populations and include additional minority groups in order to investigate whether these finding are generalizable. Furthermore, future studies should also investigate additional factors involved in the provider-patient relationship that may also be affected by acculturation levels. Ultimately, this study provides results that would inform the creation of an intervention to establish a causal relationship between the provider-patient interactions and satisfaction with care.

\section{ACKNOWLEDGEMENTS}

This work was supported by the National Cancer Institute of the National Institutes of Health under award numbers P20 CA174292 and P20 CA174188. This work was also supported by the National Center for Research Resources and the National Center for Advancing Translational Sciences, National Institute of Health, through Grant UL1 TR000153 and KL2 TR000147.

\section{CONFLicts OF InTEREST Disclosure}

The authors declare no conflicts of interest.

\section{REFERENCES}

[1] Breastcancer.org. U.S. Breast Cancer Statistics. Available from: http://www.breastcancer.org/symptoms/understand_bc/ statistics

[2] Diefenbach M, Turner G, Carpenter KM, et al. Cancer and patientphysician communication. J Health Commun. 2009; 14 Suppl 1: 57-65. PMid:19449269. https://doi .org/10.1080/10810730 902814079

[3] Ong LM, de Haes JC, Hoos AM, et al. Doctor-patient communication: a review of the literature. Soc Sci Med. 1995; 40(7): 903-918.
https://doi.org/10.1016/0277-9536(94)00155-M

[4] Thind A, Hoq L, Diamant A, et al. Satisfaction with care among low-income women with breast cancer. J Womens Health (Larchmt) 2010; 19(1): 77-86. PMid:20088662. https://doi .org/10.108 9/jwh.2009.1410

[5] Brundage MD, Feldman-Stewart D, Tishelman C. How do interventions designed to improve provider-patient communication work? Illustrative applications of a framework for communication, Acta Oncologica. 2010; 49(2): 136-143. PMid:20100151. https://doi.org/10.3109/02841860903483684 
[6] Heisler M, Bouknight RR, Hayward RA, et al. The relative importance of physician communication, participatory decision making, and patient understanding in diabetes self-management. J Gen Intern Med. 2002; 17(4): 243-252. PMid:11972720. https ://doi.org/ $10.1046 / j .1525-1497.2002 .10905 . x$

[7] Katz SJ, Lantz PM, Janz NK, et al. Patient involvement in surgery treatment decisions for breast cancer. J Clin Oncol. 2005; 23(24): 5526-5533. PMid:16110013. https://doi.org/10.1200/JC0. 2005.06.217

[8] Liang W, Burnett CB, Rowland JH, et al. Communication between physicians and older women with localized breast cancer: implications for treatment and patient satisfaction. J Clin Oncol. 2002; 20(4): 1008-1016. PMid:11844824. https ://doi.org/10.1200/ JCO. 20.4.1008

[9] Piette JD, Heisler M, Krein S, et al. The Role of Patient-Physician Trust in Moderating Medication Nonadherence Due to Cost Pressures. Arch Intern Med. 2005; 165(15): 1749-1755. PMid:16087823. https://doi.org/10.1001/archinte.165.15.1749

[10] Ashraf AA, Colakoglu S, Nguyen JT, et al. Patient involvement in the decision-making process improves satisfaction and quality of life in postmastectomy breast reconstruction. J Surg Res. 2013; 184(1): 665 670. PMid:23706394. https : //doi.org/10.1016/j.jss. 2013 .04 .057

[11] Vogel BA, Leonhart R, Helmes AW. Communication matters: the impact of communication and participation in decision making on breast cancer patients' depression and quality of life. Patient Educ Couns. 2009; 77(3): 391-397. PMid:19796910. https://doi.or $\mathrm{g} / 10.1016 / \mathrm{j} \cdot \mathrm{pec} .2009 .09 .005$

[12] Wildes KA, Miller AR, de Majors SS, et al. The satisfaction of Latina breast cancer survivors with their healthcare and health-related quality of life. J Womens Health (Larchmt). 2011; 20(7): 1065-1074. PMid:21736447. https://doi.org/10.1089/jwh.2010.2141

[13] Katz SJ, Wallner LP, Abrahamse PH, et al. Treatment experiences of Latinas after diagnosis of breast cancer. Cancer. 2017; 123(16): 3022-3030. PMid:28398629. https ://doi .org/10.1002/cncr .30702

[14] Napoles-Springer AM, Livaudais JC, Bloom J, et al. Information exchange and decision making in the treatment of Latina and white women with ductal carcinoma in situ. J Psychosoc Oncol. 2007; 25(4): 19-36. PMid:18032263. https://doi.org/10.1300/J0 77v25n04_02

[15] Thind A, Hoq L, Diamant A, et al. Satisfaction with care among low-income women with breast cancer. J Womens Health (Larchmt) 2010; 19(1): 77-86. PMid:20088662. https ://doi.org/10.108 9/jwh.2009.1410

[16] Yanez B, Stanton AL, Maly RC. Breast cancer treatment decision making among Latinas and non-Latina Whites: a communication model predicting decisional outcomes and quality of life. Health Psychol. 2012; 31(5): 552-561. PMid:22746263. https: //doi.org/10.1037/a0028629

[17] Katz SJ, Lantz PM, Paredes Y, et al. Breast cancer treatment experiences of Latinas in Los Angeles County. American Journal of Public Health. 2005; 95(12): 2225-2230. PMid:16257945. https : //doi.org/10.2105/AJPH. 2004.057950

[18] Hawley ST, Janz NK, Hamilton A, et al. Latina patient perspectives about informed treatment decision making for breast cancer. Patient education and counseling. 2008; 73(2): 363-370. PMid:18786799. https://doi.org/10.1016/j.pec.2008.07.036

[19] Schutt RK, Cruz ER, Woodford ML. Client satisfaction in a breast and cervical cancer early detection program: the influence of ethnicity and language, health, resources, and barriers. Women Health.
2008; 48(3): 283-302. PMid:19064463. https ://doi.org/10.1 080/03630240802463475

[20] Hawley ST, Janz NK, Lillie SE, et al. Perceptions of care coordination in a population-based sample of diverse breast cancer patients. Patient Educ Couns. 2010; 81 Suppl: S34-40. PMid:21074963. https://doi.org/10.1016/j.pec.2010.08.009

[21] Lopez ME, Kaplan CP, Napoles AM, et al. Satisfaction with treatment decision-making and treatment regret among Latinas and nonLatina whites with DCIS. Patient Educ Couns. 2014; 94(1): 83-89. PMid:24207116. https ://doi.org/10.1016/j . pec. 2013.09. 005

[22] Kaplan SH, Greenfield S, Gandek B, et al. Characteristics of physicians with participatory decision-making styles. Ann Intern Med. 1996; 124(5): 497-504. PMid:8602709. https://doi .org/10.7 326/0003-4819-124-5-199603010-00007

[23] Kaplan SH, Gandek B, Greenfield S, et al. Patient and visit characteristics related to physicians' participatory decision-making style. Results from the Medical Outcomes Study. Med Care. 1995; 33(12): 1176-1187. PMid:7500658. https : //doi.org/10.1097/000056 50-199512000-00002

[24] Heisler M, Tierney E, Ackermann RT, et al. Physicians' participatory decision-making and quality of diabetes care processes and outcomes: results from the triad study. Chronic Illn. 2009; 5: 165-76. PMid:19675116. https://doi.org/10.1177/17423953093392 58

[25] Parchman ML, Zeber JE, Palmer RF. Participatory decision making, patient activation, medication adherence, and intermediate clinical outcomes in type 2 diabetes: a STARNet study. Ann Fam Med. 2010; 8: 410-7. PMid:20843882. https://doi.org/10.1370/afm. 11 61

[26] Thom DH, Bloch DA, Segal ES. An intervention to increase patients' trust in their physicians. Stanford Trust Study Physician Group. Acad Med. 1999; 74(2): 195-198. PMid:10065061. https : //doi.org/10.1097/00001888-199902000-00019

[27] Kandula NR, Lauderdale DS. Leisure time, non-leisure time, and occupational physical activity in Asian Americans. Ann Epidemiol. 2005; 15(4): 257-265. PMid:15780772. https://doi.org/10.1 016/j. annepidem. 2004.06.006

[28] Choi SE, Ngo-Metzger Q, Billimek J, et al. Contributors to Patients' Ratings of Quality of Care Among Ethnically Diverse Patients with Type 2 Diabetes. J Immigr Minor Health. 2016; 18(2): 382389. PMid:25740551. https://doi .org/10.1007/s10903-015 $-0173-5$

[29] Sisk BA, Kang TI, Mack JW. Racial and Ethnic Differences in Parental Decision-Making Roles in Pediatric Oncology. Journal of Palliative Medicine. 2019. PMid:31408409. https://doi .org/10 $.1089 /$ jpm. 2019.0178

[30] Murray-Garcia JL, Selby JV, Schmittdiel J, et al. Racial and ethnic differences in a patient survey: patients' values, ratings, and reports regarding physician primary care performance in a large health maintenance organization. Med Care. 2000; 38: 300-310. PMid:10718355. https://doi .org/10.1097/00005650-200003000-00007

[31] Saha S, Arbelaez JJ, Cooper LA. Patient-physician relationships and racial disparities in the quality of health care. Am J Public Health. 2003; 93: 1713-1719. PMid:14534227. https://doi.org/10.2 105/AJPH.93.10.1713

[32] Alegria M, Nakash O, Johnson K, et al. Effectiveness of the DECIDE Interventions on Shared Decision Making and Perceived Quality of Care in Behavioral Health With Multicultural Patients: A Randomized Clinical Trial. JAMA Psychiatry. 2018; 75(4): 325-335. PMid:29466533. https ://doi.org/10.1001/jamapsychiatry .2017 .4585 
[33] Ernstmann N, Wirtz M, Nitzsche A, et al. Patients' Trust in Physician, Patient Enablement, and Health-Related Quality of Life During Colon Cancer Treatment. J Canc Educ. 2017; 32: 571-9. PMid:28110419. https://doi.org/10.1007/s13187-017-1166-y

[34] Birkhäuer J, Gaab J, Kossowsky J, et al. Trust in the health care professional and health outcome: a meta-analysis. PLoS ONE. 2017; 12: 1-13. PMid:28170443. https://doi.org/10.1371/journa 1.pone. 0170988

[35] Mechanic D, Meyer S. Concepts of trust among patients with serious illness. Soc Sci Med. 2000; 51(5): 657-668. https : //doi .org/10 .1016/S0277-9536(00)00014-9

[36] Sterba KR, Zapka J, LaPelle N, et al. A formative study of colon cancer surveillance care: implications for survivor-centered interventions. J Cancer Educ. 2015; 30: 719-727. PMid:25411092. https ://doi.org/10.1007/s13187-014-0756-1

[37] Hillen MA, de Haes, Hanneke CJM, et al. Cancer patients' trust in their physician - a review. Psychooncology. 2011; 20(3): 227-241. PMid:20878840. https://doi.org/10.1002/pon.1745

[38] Hasnain M, Schwartz A, Girotti J, et al. Differences in PatientReported Experiences of Care by Race and Acculturation Status. J Immigr Minor Health. 2013; 15(3): 517-524. PMid:23054545. https://doi.org/10.1007/s10903-012-9728-x

[39] Colmenares-Roa T, Huerta-Sil G, Infante-Castañeda C, et al. DoctorPatient Relationship Between Individuals with Fibromyalgia and Rheumatologists in Public and Private Health Care in Mexico. Qualitative Health Research. 2016; 26(12): 1674-1688. PMid:27578852. https://doi.org/10.1177/1049732315588742

[40] Mistry H, Levack WM, Johnson S. Enabling people, not completing tasks: patient perspectives on relationships and staff morale in mental health wards in England. BMC Psychiatry. 2015; 15:
307. PMid:26631134. https://doi .org/10.1186/s12888-015 $-0690-8$

[41] MacLeod S, Musich S, Gulyas S, et al. The impact of inadequate health literacy on patient satisfaction, healthcare utilization, and expenditures among older adults. Geriatric Nursing. 2017; 38: 334-41 PMid:28089217. https://doi.org/10.1016/j.gerinurse. 20 16.12 .003

[42] Abraído-Lanza AF, Armbrister AN, Flórez KR, et all. Toward a theory-driven model of acculturation in public health research. American Journal of Public Health. 2006; 96(8): 1342-1346. PMid:16809597. https ://doi.org/10.2105/AJPH. 2005.0649 80

[43] Pérez-Escamilla R, Putnik P. The Role of Acculturation in Nutrition, Lifestyle, and Incidence of Type 2 Diabetes among Latinos. The Journal of Nutrition. 2007; 137(4): 860-870. PMid:17374645. https ://doi.org/10.1093/jn/137.4.860

[44] Lopez-Class M, Gonzalez Castro F, Ramirez AG. Conceptions of acculturation: A review and statement of critical issues. Soc Sci Med. 2011; 72(9): 1555-1562. PMid:21489670. https://doi.org/10 .1016/j.socscimed. 2011.03 .011

[45] Acevedo-Garcia D, Sanchez-Vaznaugh EV, Viruell-Fuentes EA, et al Integrating social epidemiology into immigrant health research: A cross-national framework. Soc Sci Med. 2012; 75(12): 2060-2068. PMid:22721965. https://doi.org/10.1016/j.socscimed. 20 12.04 .040

[46] Allen JD, Caspi C, Yang M, et al. Pathways between acculturation and health behaviors among residents of low-income housing: the mediating role of social and contextual factors. Social Science \& Medicine. 2014; 123: 26-36. PMid:25462602. https : //doi.org/10.1016/j.socscimed.2014.10.034 